\title{
Biomass Evaluation of Fungi Pellets by Respiratory Activity
}

\author{
KEISUKE IWAHORI ${ }^{1}$, SHIGERU TATSUTA ${ }^{1}$, MASANORI FUJITA ${ }^{1}$, \\ and KOICHIRO YAMAKAWA ${ }^{2}$ \\ ${ }^{1}$ Department of Environmental Engineering, Faculty of Engineering, Osaka University \\ /2-1, Yamada-oka, Suita, Osaka 565, Japan \\ ${ }^{2}$ Takenaka Corporation/21-1, Ginza 8-chome, Chuo-ku, Tokyo 106, Japan
}

\begin{abstract}
A theoretical discussion on the biomass evaluation of pellet based on the respiratory activity was made and its experimental investigations were carried out using pellets formed by Aspergillus niger, of which average diameters were $2.0 \mathrm{~mm}, 5.0 \mathrm{~mm}$ and $10.0 \mathrm{~mm}$, respectively. The maximum respiration rate (Rr) was recognized when the initial TOC concentration exceeded about $5,000 \mathrm{mg} / l$. The biomass concentration is linearly related to the $\mathrm{Rr}$ value in case of the same pellet diameter. However, the $\mathrm{Rr}$ value decreased as the pellet diameter became larger in case of the same biomass concentration, because of the oxygen limitation. Comparing the theory based on the oxygen limitation with the experimental results, it was suggested that the area in $0.5-0.7 \mathrm{~mm}$ from the pellet surface was an aerobic and active area not susceptible to the oxygen limitation. It was shown by the proposed theory that the maximum respiration rate was effective as an index of biomass evaluation of pellets, which were formed by the five-day culture and of which diameter was more than $5.0 \mathrm{~mm}$.
\end{abstract}

Key words : biomass evaluation, pellet, Aspergillus niger, respiratory activity, maximum respiration rate, oxygen limitation

\section{INTRODUCTION}

Production of various materials and their use have been recently accelerated by rapid progress in the technology and improvement of the life style. These materials are often discharged into a wastewater, resulting in its quantitative and qualitative changes. It has been indicated that conventional wastewater treatment process, such as the activated sludge process, tends to be difficult to treat these materials sufficiently. Therefore, application of the entrapped immobilization method using the specified microorganisms, i.e. phenol degrading bacterium ${ }^{1)}$, recombinant bacterium ${ }^{2}$, and use of fungi ${ }^{3)-6 \text { ) }}$ which have the peculiar enzyme activities have been developed.

We have experimentally investigated starch wastewater treatment using pellets of Aspergillus niger ${ }^{6)}$. The results suggested that the pellets were applicable to the starch wastewater treatment, because of the excellent solid-liquid separation and the strong amylase activities. However, the kinetic analysis and the model simulation for design, operation and control of the wastewater treatment plant using fungi pellets are not applicable, because the biomass evaluation of pellets has not been developed. In 
this study, applying the biomass evaluation of the entrapped-immobilization method proposed by Hashimoto et $a l_{.}{ }^{7}$, a theoretical discussion on the biomass evaluation based on the respiratory activity is made and its experimental investigations are carried out using pellets formed by $A s p$. niger.

\section{THEORETICAL BACKGROUND}

The respiration rate of Asp. niger associated with glucose decomposition is generally expressed by the following equation:

$$
\frac{\mathrm{dO}_{2}}{\mathrm{dt}}=\mathrm{Y}^{\prime} \cdot\left(-\frac{\mathrm{dG}}{\mathrm{dt}}\right)+\mathrm{b}^{\prime} \cdot \mathrm{X}
$$

where $\mathrm{dO}_{2} / \mathrm{dt}$ is the respiration rate of $A s p$. niger and $-\mathrm{dG} / \mathrm{dt}$ is the glucose decomposition rate. $Y, b, G$ and $X$ are the ratio of oxygen consumed to glucose decomposed, an endogenous respiration rate constant, the glucose and the biomass concentrations, respectively.

The glucose decomposition rate can be expressed by the following equation, taking into consideration both growth of Asp. niger and production of citric acid:

$$
-\frac{d G}{d t}=Y_{G X} \cdot \frac{d X}{d t}+Y_{G C} \cdot \frac{d C}{d t}
$$

where $\mathrm{dX} / \mathrm{dt}, \mathrm{dC} / \mathrm{dt}, \mathrm{Y}_{\mathrm{GX}}$ and $\mathrm{Y}_{\mathrm{GC}}$ are the growth rate of Asp. niger, the production rate of citric acid, the inverse of yield coefficient on $A s p$. niger growth and stoichiometric coefficient of glucose to citric acid, respectively. $\mathrm{C}$ is the citric acid concentration.

The growth rate, $\mathrm{dX} / \mathrm{dt}$, is expressed as Monod type equation taking into account the autolysis of Asp. niger and the production rate, $\mathrm{dC} / \mathrm{dt}$, is as Luedeking-Piret type equation ${ }^{8)}$, respectively.

$$
\begin{aligned}
& \frac{d X}{d t}=\frac{k_{1} \cdot G}{K_{X}+G} \cdot X-b \cdot X \\
& \frac{d C}{d t}=k_{2} \cdot \frac{d X}{d t}+\frac{k_{3} \cdot G}{K_{C}+G} \cdot X
\end{aligned}
$$

where $k_{1}, k_{2}$ and $k_{3}$ are the rate constants. $K_{X}$ and $K_{C}$ are the saturation constants on growth and production, respectively. $\mathrm{b}$ is the decay coefficient.

When the respiration rate of Asp. niger is measured using glucose as a substrate, $\mathrm{dX} / \mathrm{dt}$ may be assumed to be equal to zero, because of the short measurement period. Therefore, Eqs. (2) and (4) can be approximated as follows:

$$
\begin{aligned}
& -\frac{d G}{d t}=Y_{G C} \cdot \frac{d C}{d t} \\
& \frac{d C}{d t}=\frac{k_{3} \cdot G}{K_{C}+G} \cdot X
\end{aligned}
$$

Substituting Eqs.(5) and (6) into Eq.(1) yields Eq. (7).

$$
\frac{\mathrm{dO}_{2}}{\mathrm{dt}}=\left[\mathrm{Y}^{\prime} \cdot \mathrm{Y}_{\mathrm{GC}} \cdot \frac{\mathrm{k}_{3} \cdot \mathrm{G}}{\mathrm{K}_{\mathrm{C}}+\mathrm{G}}+\mathrm{b}^{\prime}\right] \cdot \mathrm{X}
$$

If high strength glucose concentration is used for the respiration rate measurement, Eq.(7) can be approximated as the following equation because of $\mathrm{K}_{\mathrm{C}}<\mathrm{G}$ :

$$
\frac{\mathrm{dO}_{2}}{\mathrm{dt}}=\left(\mathrm{Y}^{\prime} \cdot \mathrm{Y}_{\mathrm{GC}} \cdot \mathrm{k}_{3}+\mathrm{b}^{\prime}\right) \cdot \mathrm{X}
$$

Under the conditions described above, the value of $\mathrm{dO}_{2} / \mathrm{dt}$ in Eq. (8) may be considered the maximum respiration rate $(\mathrm{Rr})$ and Eq. $(8)$ can be rewritten as follows:

$$
\mathrm{X}=\frac{\mathrm{Rr}}{\mathrm{Y}^{\prime} \cdot \mathrm{Y}_{\mathrm{GC}} \cdot \mathrm{k}_{3}+\mathrm{b}^{\prime}}
$$

As $Y^{\prime}, Y_{G C}, k_{3}$ and b' in Eq.(9) are constant, $X$ is proportional to $\mathrm{Rr}$. Therefore, the maximum respiration rate allows the evaluation of the biomass concentration.

\section{MATERIALS AND METHODS}

Microorganism Aspergillus niger $\mathrm{KCC} F$ -0086 (ATCC6275) subcultured on a CzapekDox agar medium, as shown in Table 1, was used in the experiments.

Preparation of spore suspension Sterilized water was added to a slant of Asp. niger and mixed to form a suitable solution of suspended spores. The optical density of this suspension was then adjusted to 0.5 at the wave length of $600 \mathrm{~nm}$ (equivalent to $10^{6}$ spores per $\mathrm{ml}$ ). 
Table 1 Composition of Czapek-Dox agar medium

\begin{tabular}{|c|c|}
\hline Glucose & $25.0 \mathrm{~g} / \mathrm{l}$ \\
\hline $\mathrm{NaNO}_{3}$ & $3.0 \mathrm{~g} / \mathrm{l}$ \\
\hline $\mathrm{K}_{2} \mathrm{HPO}_{4}$ & $1.0 \mathrm{~g} / \mathrm{l}$ \\
\hline $\mathrm{KCl}$ & $0.5 \mathrm{~g} / \mathrm{l}$ \\
\hline $\mathrm{MgSO}_{4} \cdot 7 \mathrm{H}_{2} \mathrm{O}$ & $0.5 \mathrm{~g} / \mathrm{l}$ \\
\hline $\mathrm{FeSO}_{4} \cdot 7 \mathrm{H}_{2} \mathrm{O}$ & $0.01 \mathrm{~g} / \mathrm{l}$ \\
\hline Agar & $15.0 \mathrm{~g} / \mathrm{l}$ \\
\hline TOC & $1000 \mathrm{mg} / \mathrm{l}$ \\
\hline $\mathrm{pH}^{\mathrm{a}}$ & 5.6 \\
\hline
\end{tabular}

${ }^{\mathrm{a}} \mathrm{pH}$ was adjusted by the sterilized $2 \mathrm{~N} \mathrm{HCl}$.

Table 2 Average diameter and number of pellets used in each experiment

\begin{tabular}{|c|c|c|}
\hline \multirow{2}{*}{ Run No. } & \multicolumn{2}{|l|}{ Pellet } \\
\hline & $\begin{array}{c}\text { Average diameter } \\
(\mathrm{mm})\end{array}$ & $\begin{array}{c}\text { Number } \\
(\mathrm{N})\end{array}$ \\
\hline 1 & $2.0 \pm 0.5$ & $\begin{array}{l}300 \\
600 \\
900\end{array}$ \\
\hline 2 & $5.0 \pm 0.5$ & $\begin{array}{l}19 \\
38 \\
58\end{array}$ \\
\hline 3 & $10.0 \pm 0.5$ & $\begin{array}{l}2 \\
5 \\
7\end{array}$ \\
\hline
\end{tabular}

Medium A Czapek-Dox medium without agar was used for experiments. This medium was diluted to have a prescribed TOC concentration by deionized water.

Preparation of pellets Three hundred $\mathrm{ml}$ Erlenmeyer flasks were filled with $100 \mathrm{~m} l$ of Czapek-Dox medium respectively. Then, each flask was inoculated with a fixed $G$ value by a rotational shaking the same as that of Fujita et $a l^{9)}$ From the pellets formed by five-day culture, those of $2.0 \mathrm{~mm}, 5.0 \mathrm{~mm}$, and $10.0 \mathrm{~mm}$ in diameter were chosen, as shown in Table 2, and thoroughly washed with deionized water before being used in the experiments. It is obvious from

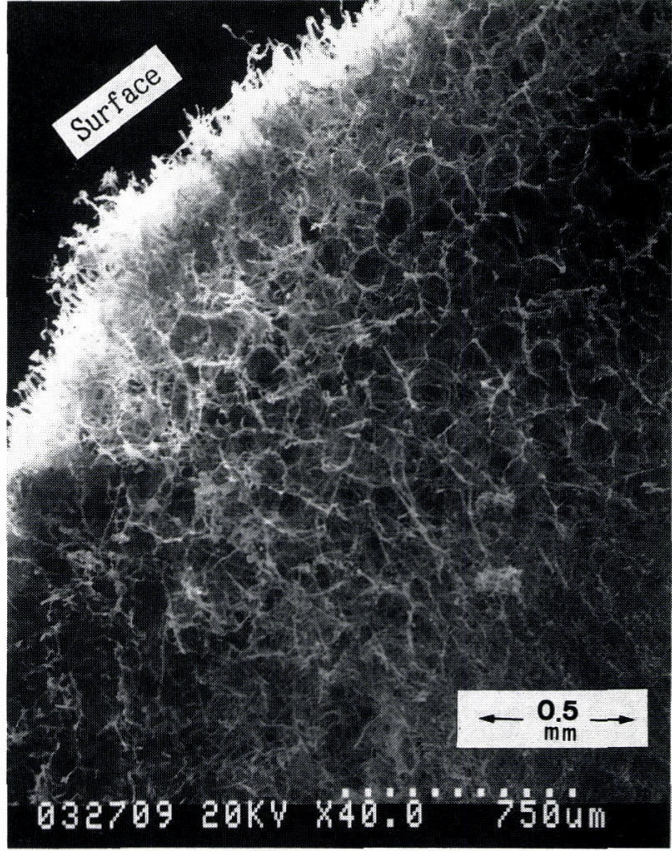

Fig. 1 Electron microscopic photograph of a pellet. ( $5.0 \mathrm{~mm}$ in diameter)

fig. 1 that these pellets have a highly porous structure.

Methods A medium of predetermined TOC concentration (oxygen enriched by aeration) and the pellets shown in Table 2 were placed into a $200 \mathrm{~m} l$ BOD incubation bottle. This was kept in a constant-temperature water bath at $20^{\circ} \mathrm{C}$ and the respiration rate was measured according to the standard method ${ }^{10)}$. At the end of the experiment, the dry weight of pellet was measured. The TOC concentrations before and after experiment were measured to confirm that there was no growth of biomass.

\section{RESULTS AND DISCUSSION}

Initial TOC concentration affecting respiration rate of pellets Figure 2 shows the relationship between the respiration rate and initial TOC concentration as the representative. It is found that the respiration rate rises as the TOC concentration is higher, regardless of the 


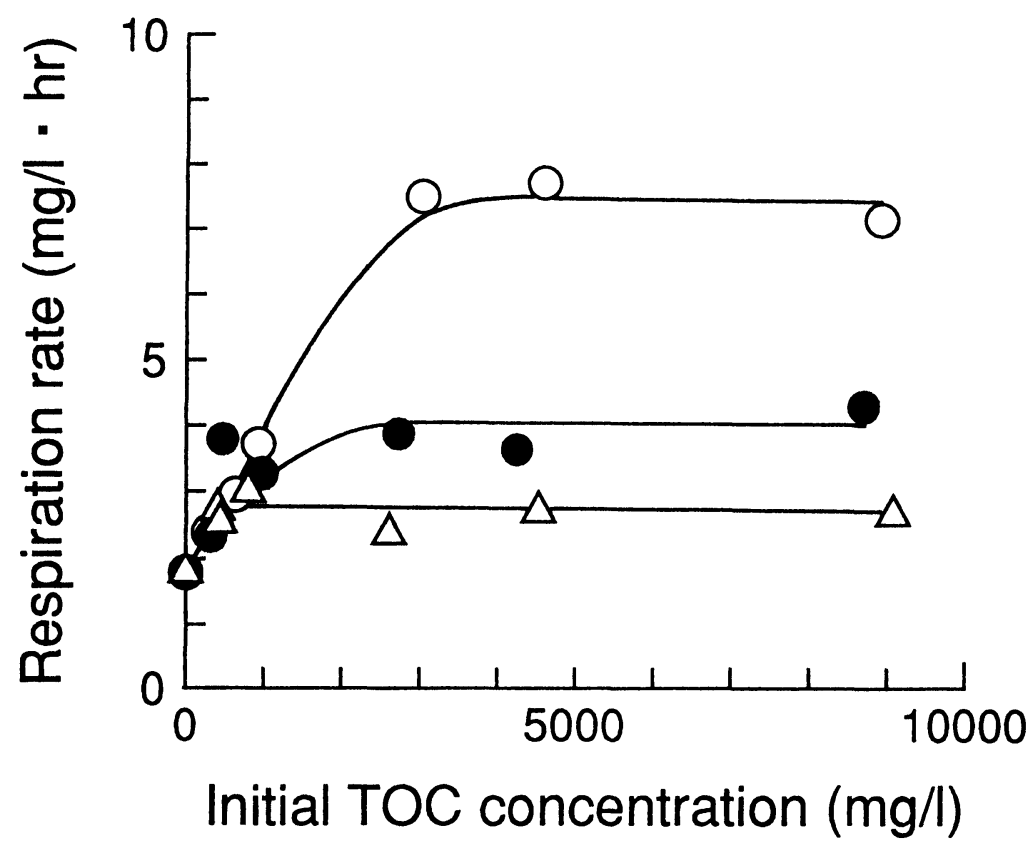

Fig. 2 Relationship between initial TOC concentration of medium and respiration rate of pellet. Symbols: $\bigcirc$, Pellet No. is 300 in Run 1; O, Pellet No. is 19 in Run 2; $\triangle$, Pellet No. is 2 in Run 3.

number or diameter of pellets. However, the respiration rate becomes almost constant when the TOC concentration exceeds about $5,000 \mathrm{mg} / l$. Results of other experimental conditions are similar to those in this figure. Therefore, the respiration rate at this steady state can be regarded as the maximum respiration rate $(\mathrm{Rr})$.

The relationship between $\mathrm{Rr}$ as measured for each run and the biomass concentration $(\mathrm{X})$ is shown in Fig. 3. The relationships of $\mathrm{X}=27.62$. $\mathrm{Rr}$ for Run $1, \mathrm{X}=31.73 \cdot \mathrm{Rr}$ for Run 2 and $\mathrm{X}=$ $51.42 \cdot \mathrm{Rr}$ for Run 3 were obtained, respectively. It is obvious that the relationship is given by the theoretical equation, Eq.(9), in case of the same pellet diameter. However, the coefficient of Eq. (9), $1 /\left(\mathrm{Y}^{\prime} \cdot \mathrm{Y}_{\mathrm{GC}} \cdot \mathrm{k}_{3}+\mathrm{b}^{\prime}\right)$, tends to be lower as the pellet diameter becomes smaller. This result shows that, in case of the same biomass concentration, $\mathrm{Rr}$ decreases as the pellet diameter becomes larger. Therefore, it was suggested that oxygen was limited inside the pellet and its respiratory activity was degraded as the pellet diameter became larger.

Respiratory activity of pellet based on oxygen limitation A theoretical equation describing the relationship between $\mathrm{Rr}$ and the biomass concentration for the same diameter of pellet was developed and verified by the experimental investigation. This result was similar to that immobilized by PVA-boric acid method ${ }^{7}$. However, the same biomass evaluation of fungi pellets as that of the entrapped-immobilized microorganisms is not suitable, because of the posibility of oxygen supply being limited inside the pellets as they grow. Therefore, the biomass evaluation of pellets by the respiratory activity based on the oxygen limitation was investigated as the following assumptions:

(a) The DO concentration decreases linearly from the pellet surface to the interior, as shown in Fig.4.

(b) The respiration rate is constant until 


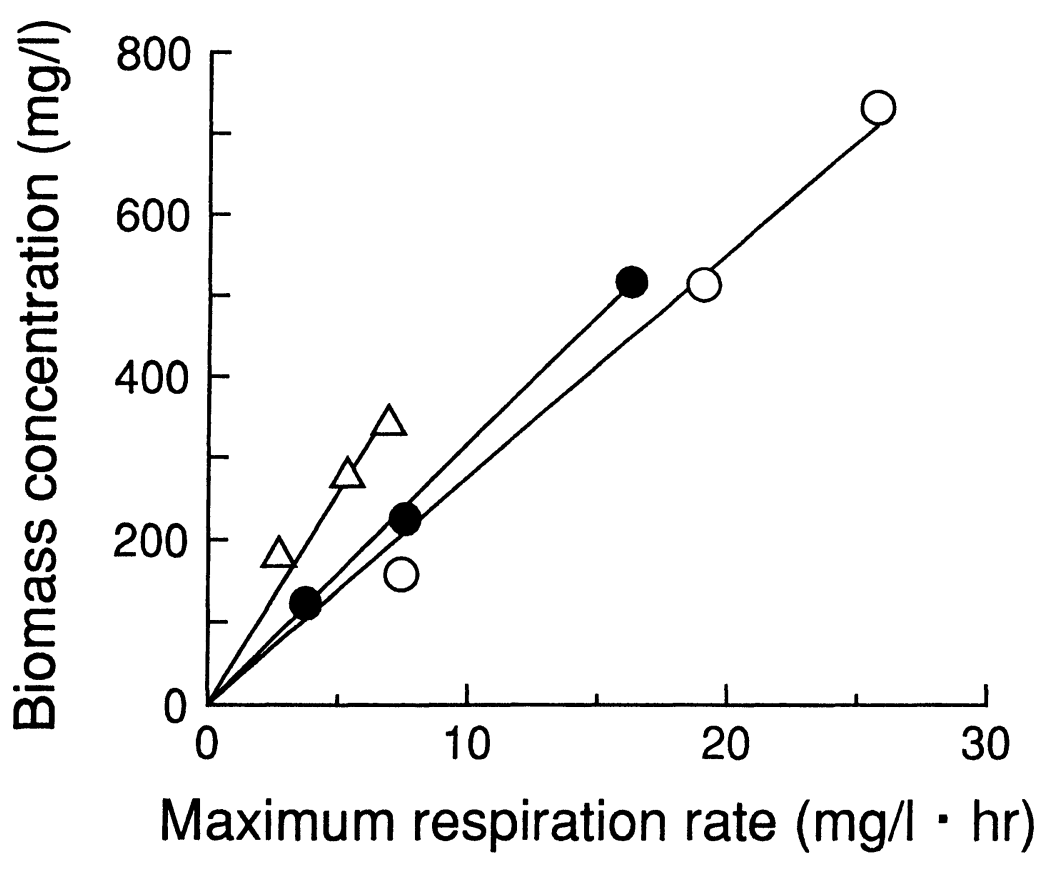

Fig. 3 Relationship between maximum respiration rate and biomass concentration. Symbols: $\bigcirc$, Run 1; $\bigcirc$, Run 2; $\triangle$, Run 3.

restricted by the lack of oxygen.

(c) The respiration rate decreaeses linearly below $\mathrm{A}^{*} \mathrm{mg} / l$ of $\mathrm{DO}$ concentration.

The respiration rate per one pellet, $\mathrm{Rr}^{\prime}$, can be calculated using the following equation:

$$
\begin{aligned}
\mathrm{Rr}^{\prime} & =\frac{1}{\mathrm{~V}} \cdot \int_{0}^{\alpha}\left\{-\mathrm{h}(\alpha-\beta) \cdot 4 \pi(\mathrm{r}-\mathrm{x})^{2}\right\} \mathrm{dx} \\
& +\frac{1}{\mathrm{~V}} \cdot \int_{\alpha}^{\beta}\left\{-\mathrm{h}(\mathrm{x}-\beta) \cdot 4 \pi(\mathrm{r}-\mathrm{x})^{2}\right\} \mathrm{dx}(10)
\end{aligned}
$$

where $\mathrm{V}$ and $\mathrm{r}$ are the volume of medium and the diameter of pellet, respectively. The following equation is obtained by solving Eq. (10):

$$
\begin{aligned}
\mathrm{Rr}^{\prime}= & -\frac{4 \pi \mathrm{h}}{\mathrm{V}} \cdot\left(\frac{\alpha^{4}}{12}-\mathrm{r} \cdot \frac{\alpha^{3}}{3}+\mathrm{r}^{2} \cdot \frac{\alpha^{2}}{2}\right. \\
& \left.-\mathrm{r}^{2} \cdot \frac{\beta^{2}}{2}+\mathrm{r} \cdot \frac{\beta^{3}}{3}-\frac{\beta^{4}}{12}\right)
\end{aligned}
$$

If the pellet diameter is sufficiently large, the high-order terms of $\alpha$ and $\beta$ may be neglected and Eq.(11) is approximated as the following.

$$
\mathrm{Rr}^{\prime}=-\frac{4 \pi \mathrm{h}}{\mathrm{V}}\left(\mathrm{r}^{2} \frac{\alpha^{2}}{2}-\mathrm{r}^{2} \cdot \frac{\beta^{2}}{2}\right)
$$

As the initial DO concentration, $\mathrm{A}_{0}$, at the $\mathrm{Rr}$ measurement is about $4.0 \mathrm{mg} / l$ and the DO concentration, $\mathrm{A}^{*}$, at which microorganisms are not generally limited by the oxygen is about 0.5 $\mathrm{mg} / l^{11)}$, the relationship of $\alpha=7 \beta / 8$ can be established and $\mathrm{Rr}^{\prime}$ is expressed as follows:

$$
R r^{\prime}=\frac{15 \pi \cdot h \cdot r^{2} \cdot \beta^{2}}{32 \cdot V}
$$

Trial and error method was used to calculate a value corresponding to the measured Rr' value by changing $\beta$ as shown in Eq. (13). $\beta$ was presumed to be $0.5-0.7 \mathrm{~mm}$ as a result. In other words, it was suggested that the area in $0.5-0.7$ $\mathrm{mm}$ from the pellet surface was an aerobic and active area not susceptible to the oxygen limitation.

Assuming that the density of pellet is $\rho$, the biomass concentration per pellet, $\mathrm{X}$, can be expressed by the following equation:

$$
\mathrm{X}^{\prime}=\frac{4 \cdot \pi \cdot \mathrm{r}^{3}}{3 \cdot \mathrm{V} \cdot \rho}
$$




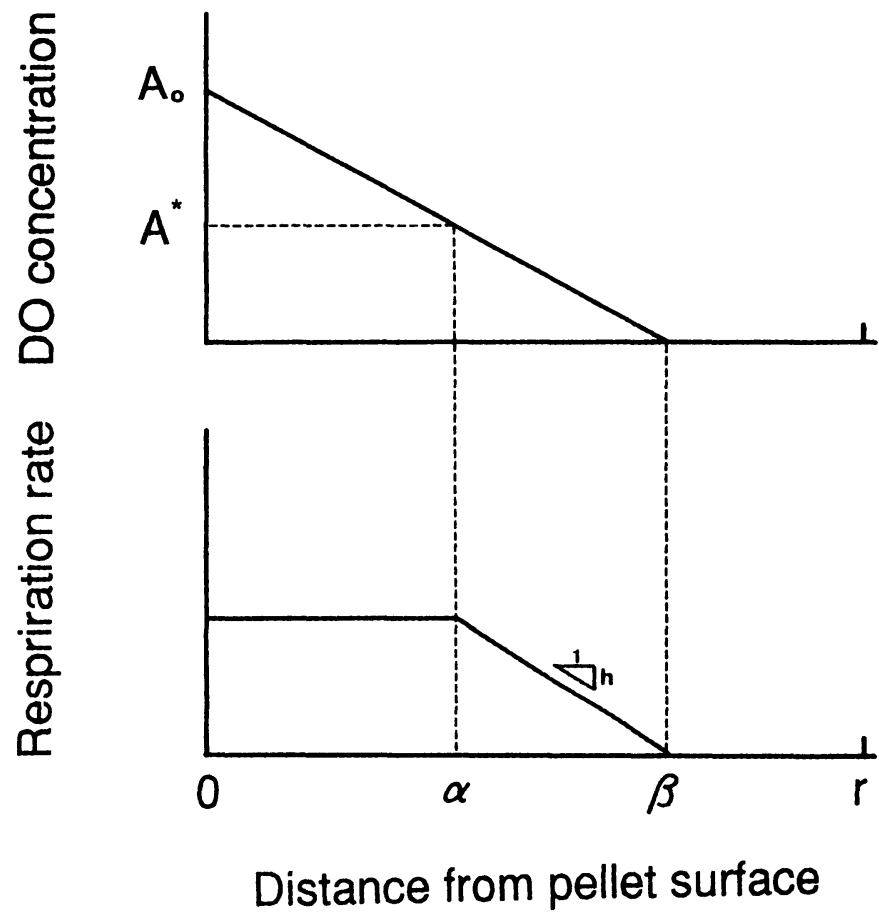

Fig. 4 Schematic diagram of both $D O$ concentration and respiration rate profiles in pellet. $\mathrm{Rr}^{\prime}=-\mathrm{h} \cdot(\alpha-\beta)$ when $\mathrm{x}<\alpha, \mathrm{Rr}^{\prime}=-\mathrm{h}(\mathrm{x}-\beta)$ when $\alpha<\mathrm{x}<\beta, \mathrm{Rr}^{\prime}=0$ when $\beta<\mathrm{x}<\mathrm{r}$.

If the number of pellets used in the experiments is $\mathrm{n}$, the biomass concentration $(\mathrm{X})$ and the maximum respiration rate $(\mathrm{Rr})$ are expressed as $R r=n \cdot R r^{\prime}$ and $X=n \cdot X$, respectively. Therefore, the biomass concentration can be derived combining with Eqs. (13) and (14) as follows:

$$
\mathrm{X}=\frac{128 \cdot \rho \cdot \mathrm{r}}{45 \cdot \mathrm{h} \cdot \beta^{2}} \cdot \mathrm{Rr}
$$

If $\mathrm{h}, \beta$ and $\rho$ are constant regardless of pellet diameter, the biomass concentration may be expressed as a function of the $\mathrm{Rr}$ value and the pellet diameter. The relationship between the coefficient obtained in Fig. 3, i.e. 128 $\rho \cdot \mathrm{r} /(45 \cdot$ $\mathrm{h} \cdot \beta^{2}$ ) and the pellet diameter is shown in Fig. 5. It is obvious that the coefficient is linearly related to the pellet diameter in case of Runs 2 and 3. However, Run 1 seems to be distinctly different from Runs 2 and 3. This result was thought that $\mathrm{h}$ or $\beta$ value in Run 1 was lower than those in Runs 2 and 3 because of the shorter diameter. Therefore, it was concluded that the maximum respiration rate was effective as an index of biomass evaluation of pellets, which were formed by the five-day culture and of which diameter was more than $5.0 \mathrm{~mm}$.

\section{CONCLUSIONS}

A theoretical discussion on the biomass evaluation of pellet based on the respiratory activity was made and its experimental investigations were carried out. The results obtained are summarized as the following.

(1) The respiration rate of pellets, of which average diameters were $2.0 \mathrm{~mm}, 5.0 \mathrm{~mm}$ and 10.0 $\mathrm{mm}$, respectively, became almost constant when the initial TOC concentration exceeded about $5,000 \mathrm{mg} / \mathrm{l}$. This respiration rate was recognized as the maximum respiration rate of pellets $(\mathrm{Rr})$. (2) The biomass concentration is linearly related to the $\mathrm{Rr}$ value in case of the same pellet diameter. However, the $\mathrm{Rr}$ value decreased as 


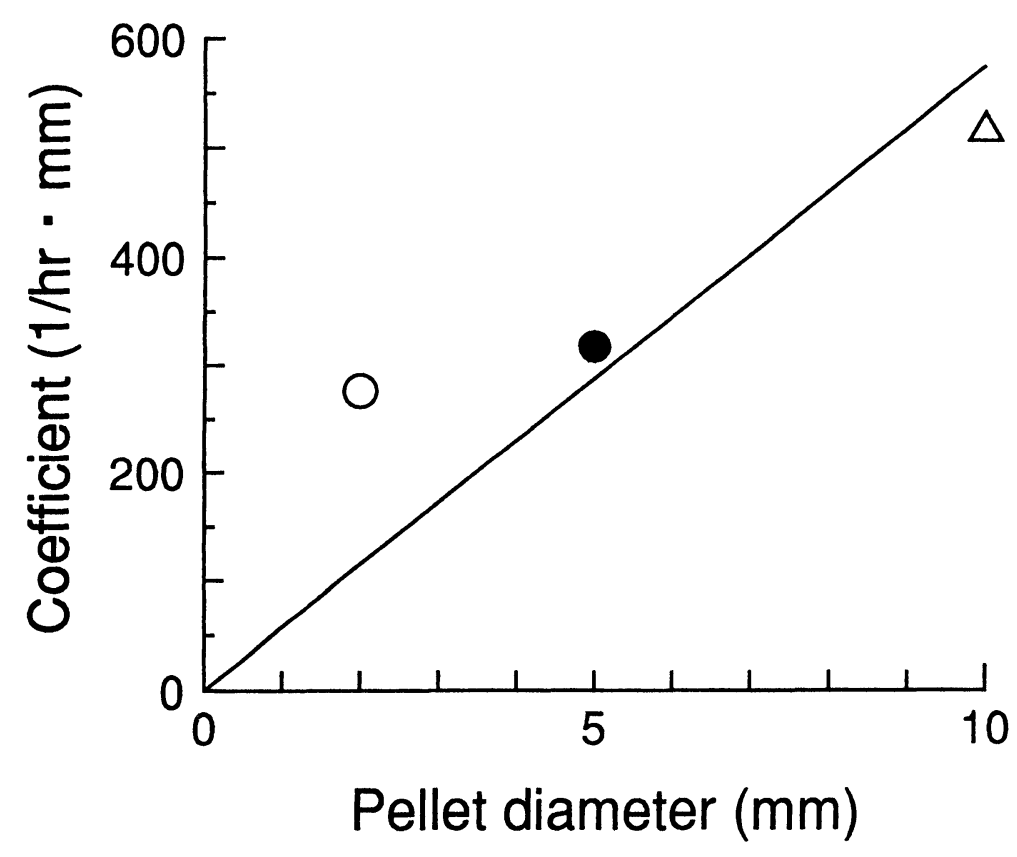

Fig. 5 Relationship between pellet diameter and coefficient in Fig. 3. The coefficient is the same as the proportional constant of Eq. (15). Symbols: $\bigcirc$, Run 1; 0 , Run 2; $\triangle$, Run 3.

the pellet diameter became larger in case of the same biomass concentration, because of the oxygen limitation.

(3) The theory of biomass evaluation of pellets based on the oxygen limitation was developed. Comparing with the experimental results, it was suggested that the area in $0.5-0.7 \mathrm{~mm}$ from the pellet surface was an aerobic and active area not susceptible to the oxygen limitation. Moreover, using the proposed theory, it was concluded that the maximum respiration rate was effective as an index of biomass evaluation of pellets, which were formed by the five-day culture and of which diameter was more than $5.0 \mathrm{~mm}$.

\section{NOMENCLATURE}

$\mathrm{A}_{0} \quad$ : Initial DO concentration of medium, $\mathrm{mg} / l$

$\mathrm{A}^{*} \quad: \mathrm{DO}$ concentration at which microorganisms are not limited by oxygen, $\mathrm{mg} / l$

b : Decay coefficient, $1 / \mathrm{hr}$

b' : Endogenous respiration rate constant, $1 / \mathrm{hr}$

C : Citric acid concentration, $\mathrm{mg} / \mathrm{l}$

$\mathrm{dC} / \mathrm{dt} \quad$ : Production rate of citric acid, $\mathrm{mg} / l \cdot \mathrm{hr}$

$-\mathrm{dG} / \mathrm{dt} \quad$ : Glucose decomposition rate, $\mathrm{mg} / l \cdot \mathrm{hr}$

$\mathrm{dO}_{2} / \mathrm{dt} \quad$ : Respiration rate of pellets, $\mathrm{mg} / l \cdot \mathrm{hr}$

$\mathrm{dX} / \mathrm{dt} \quad$ : Growth rate of pellets, $\mathrm{mg} / l \cdot \mathrm{hr}$

$\mathrm{G}$ : Glucose concentration, $\mathrm{mg} / l$

$\mathrm{h} \quad$ : Consumed oxygen per unit of distance, $\mathrm{mg} / \mathrm{mm}$

$\mathrm{k}_{1} \quad$ : Rate constant, $1 / \mathrm{hr}$

$\mathrm{k}_{2} \quad$ : Rate constant, -

$\mathrm{k}_{3} \quad$ : Rate constant, $1 / \mathrm{hr}$

$\mathrm{K}_{\mathrm{X}} \quad$ : Saturation constant on growth, $\mathrm{mg} / \mathrm{l}$

$\mathrm{K}_{\mathrm{C}} \quad$ : Saturation constant on production, $\mathrm{mg} / l$

$\mathrm{n} \quad$ : Number of pellets, $\mathrm{N}$

$\mathrm{r} \quad$ : Diameter of pellet, $\mathrm{mm}$

$\mathrm{Rr} \quad$ : Maximum respiration rate, $\mathrm{mg} / l \cdot \mathrm{hr}$ 


\begin{tabular}{|c|c|}
\hline $\mathrm{Rr}^{\prime}$ & $\begin{array}{l}\text { Respiration rate per pellet, mg } \\
l l \cdot \mathrm{hr} \cdot \mathrm{N}\end{array}$ \\
\hline $\mathrm{V}$ & : Volume of medium, $\mathrm{m} l$ \\
\hline $\mathrm{X}$ & $\begin{array}{l}\text { Biomass concentration of pellets, } \mathrm{mg} \\
/ l\end{array}$ \\
\hline$X^{\prime}$ & $\begin{array}{l}\text { Biomass concentration per pellet, mg } \\
/ l \cdot \mathrm{N}\end{array}$ \\
\hline $\mathrm{Y}_{\mathrm{GX}}$ & : Inverse of yield coefficient, - \\
\hline $\mathrm{Y}_{\mathrm{GC}}$ & $\begin{array}{l}\text { Stoichiometric coefficient of glucose } \\
\text { to citric acid, - }\end{array}$ \\
\hline$Y^{\prime}$ & $\begin{array}{l}\text { Ratio of oxygen consumed to glucose } \\
\text { decomposed, - }\end{array}$ \\
\hline$\alpha$ & : Critical point of rate limitation, mm \\
\hline$\beta$ & : Critical point of anaerobic area, $\mathrm{mm}$ \\
\hline$\rho$ & Density of pellet, $\mathrm{mg} / \mathrm{l}$ \\
\hline
\end{tabular}

\section{REFERENCES}

1) Hashimoto,S., Iwahori,K., and Iwagami,A.: Studies on phenol wastewater treatment under high volumetric loading by immobilized phenoldegrading bacterium, Res. J. Japan Sewage Works Assoc., 28 (330), 67-75 (1991) (in Japanese)

2 ) Fujita,M., Ike,M., and Hashimoto,S.: Feasibility of wastewater treatment using genetically engineered microorganisms, Water Res., 25(8), 979-984 (1991)

3 ) Huynh,V.B., Chang,H., Joyce,T.W., and Kirk,T.K.: Dechlorization of chloro-organics by white-rot fungus, TAPPI, 68, 98-101 (1985)
4 ) Bumpus,J.A. and Aust,S.D.: Biodegradation of DDT [1,1,1:trichloro-2,2-bis (4-chlorophenyl) ethane] by the white rot fungus Paranerochaete chrysosporium, Appl. envir. Microbiol., 53, 2001-2008 (1987)

5 ) Gordon,A.L., Piero,M.A., and Daewon,P.: Reactor design for hazardous waste treatment using a white rot fungus, Water Res., 24, 75-82 (1990)

6 ) Fujita,M., Iwahori,K., and Yamakawa,K.: Pellet formation of fungi and its application to starch wastewater treatment, Wat. Sci. \& Technol., 28 (2), 267-274 (1993)

7 ) Hashimoto,S., Iwahori,K., and Hosokawa,A.: Kinetic analysis on entrapped-Immobilized activated sludge process using respiration rate as an index of biomass, Res. J. Japan Sewage Works Assoc., 30 (364), 108-116 (1993) (in Japanese)

8 ) Luedeking,R. and Piret,E.L.: A kinetic study of the lactic acid fermentation. Batch process at controlled pH, J. Biochem. Microbiol. Technol. Eng., 1(4), 393-412 (1959)

9 ) Fujita,M., Iwahori,K., Tatsuta,S., and Yamakawa,K.: Analysis of pellet formation of Aspergillus niger based on shear stress, J. Ferment. Bioeng., 78(5), 368-373 (1994)

10) Japan Sewage Works Assoc.: Standard methods for the examination of wastewater, 288-289 (1984)

11) Yamada,K. and Yano,T.: Fundamental studies on the aerobic fermentation. Part VII. Oxygen transfer in gluconic acid fermentation by $A s p$. niger, Agric. Biol. Chem., 34 (6), 523-527 (1960) (in Japnese)

(Submitted 1994. 9.26)

(Accepted 1994.10.18) 